\title{
La Bretagne Linguistique en quelques chiffres
}

\section{(2) OpenEdition}

Journals

Édition électronique

URL : http://journals.openedition.org//bl/451

DOI : $10.4000 / \mathrm{lbl} .451$

ISSN : 2727-9383

Éditeur

Université de Bretagne Occidentale - UBO

\section{Édition imprimée}

Date de publication : 1 mars 2016

Pagination : $9-13$

ISBN : 979-10-92331-24-0

ISSN : 1270-2412

Référence électronique

"La Bretagne Linguistique en quelques chiffres », La Bretagne Linguistique [En ligne], 20 | 2016, mis en ligne le 01 mai 2020, consulté le 01 octobre 2020. URL : http://journals.openedition.org//bl/451 ; DOI https://doi.org/10.4000/lbl.451

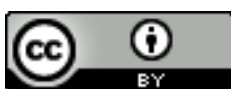

La Bretagne Linguistique est mise à disposition selon les termes de la Licence Creative Commons Attribution 4.0 International. 


\section{La Bretagne Linguistique en quelques chiffres}

Il ne s'agit pas de faire ici une histoire de la revue mais un bilan de ce que représentent 20 numéros de La Bretagne Linguistique. Nous fournissons donc au lecteur curieux un matériau brut de chiffres et de statistiques en partant du contenu des différents volumes de la revue.

La Bretagne linguistique, ce sont :

- Des rencontres :

55 journées de séminaire

2 colloques ${ }^{1}$

1 symposium $^{2}$

- Des numéros :

20 numéros en l'espace de 31 ans

En moyenne 15 articles par numéro

- Des auteurs :

188 auteurs différents

332 signatures d'articles

De 1 à 12 articles par auteur

Qui sont-ils?

$76 \%$ d'hommes et $24 \%$ de femmes

$66 \%$ de chercheurs statutaires, $21 \%$ de chercheurs non professionnels, $13 \%$ de doctorants

$40 \%$ d'auteurs locaux, $38 \%$ d'auteurs nationaux, $22 \%$ d'auteurs internationaux

1. «Badume - Standard - Norme / Le Double Jeu de la langue », 2-4 juin 1994, cf. La Bretagne linguistique, $\mathrm{n}^{\circ} 10$, Brest, CRBC, 1996 et «Y a-t-il une exception sociolinguistique française? », 5-7 juin 1997, cf. La Bretagne Linguistique, n 12, Brest, CRBC, 1998.

2. Consacré au dictionnaire de Coëtanlem, cf. La Bretagne Linguistique, n 17, Brest, CRBC, 2013. 
- Des articles :

306 articles au total

Différents domaines représentés :

Sociolinguistique et sociolinguistique historique

Dialectologie et géographie linguistique

Linguistique, linguistique historique, phonologie

Littérature

Ethnologie

Histoire, archéologie

Orthographe, lexicologie, anthroponymie, toponymie

Répartition des différents domaines scientifiques dans les 20 numéros :

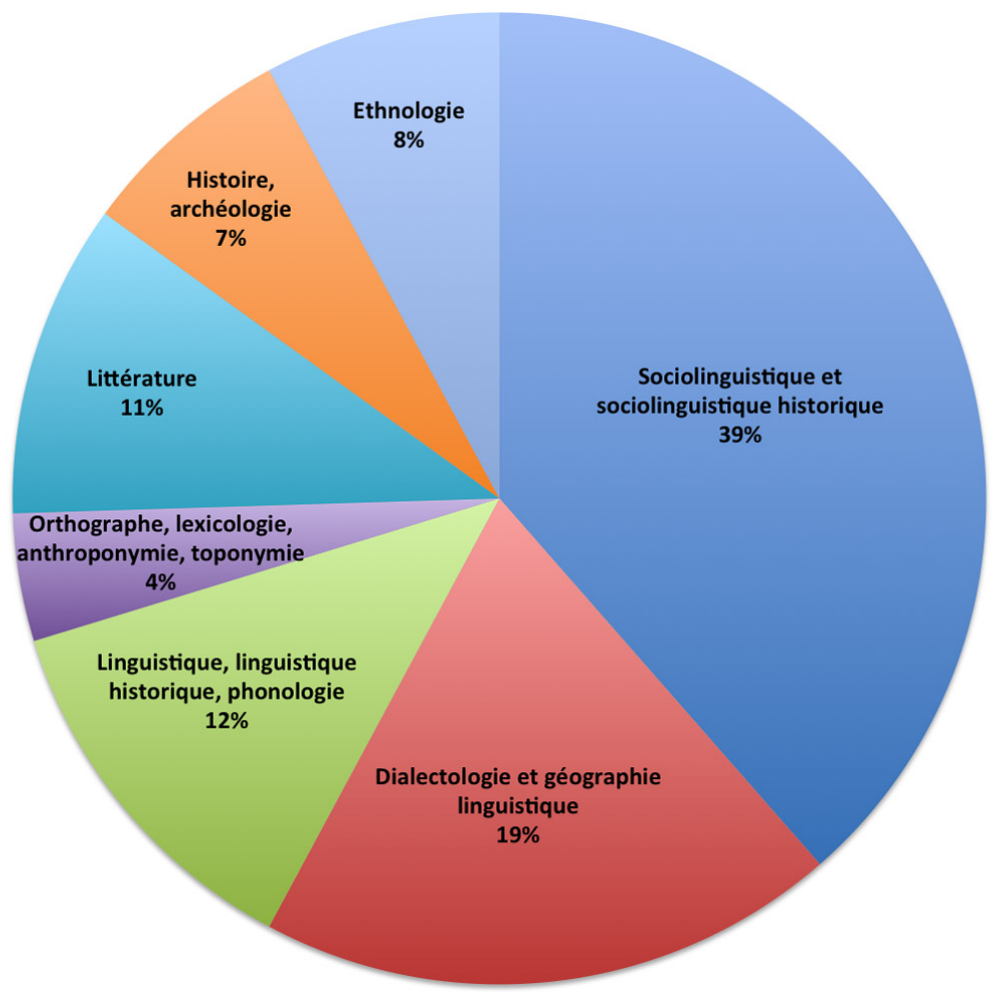




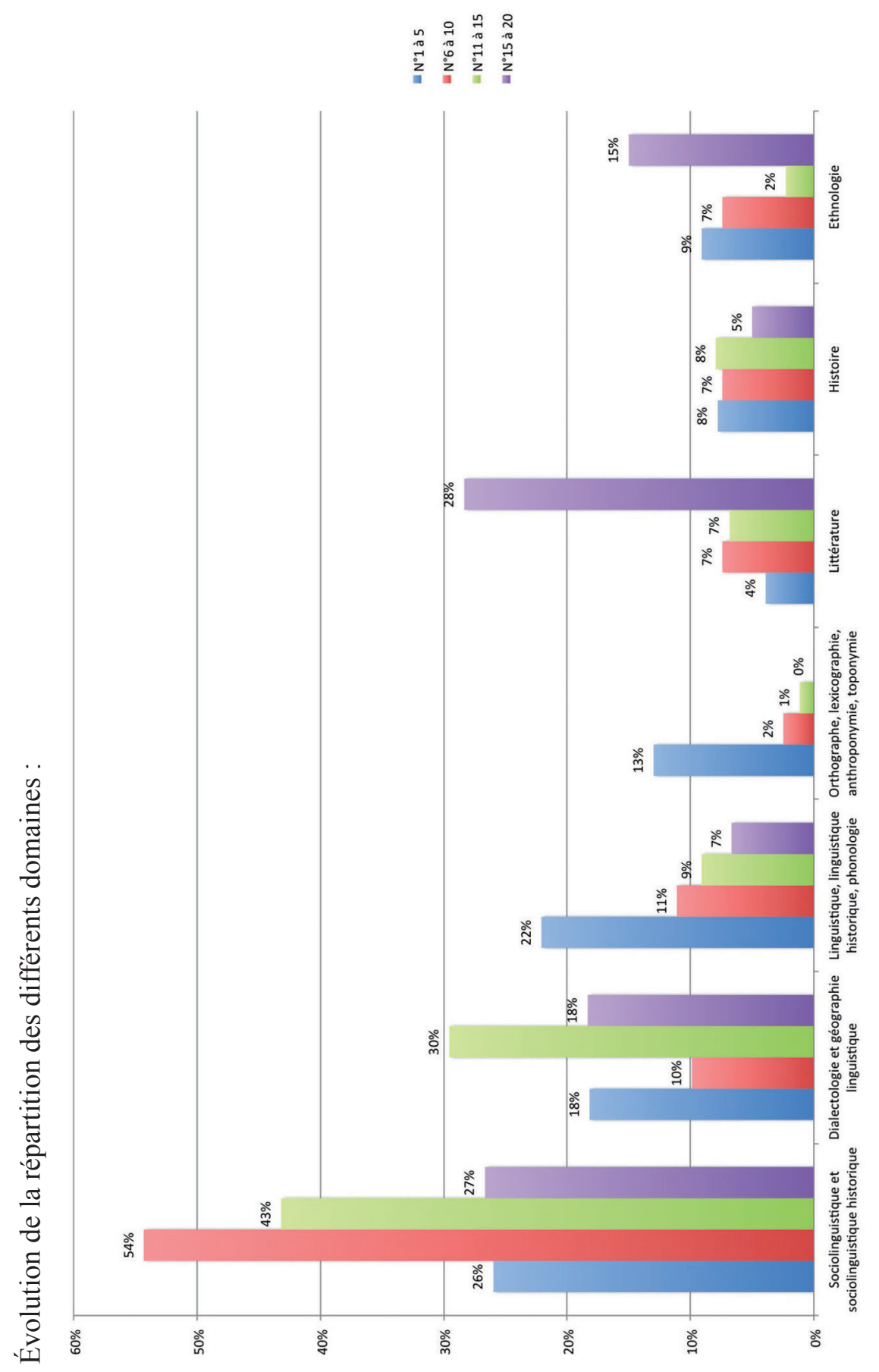


Répartition par statut :

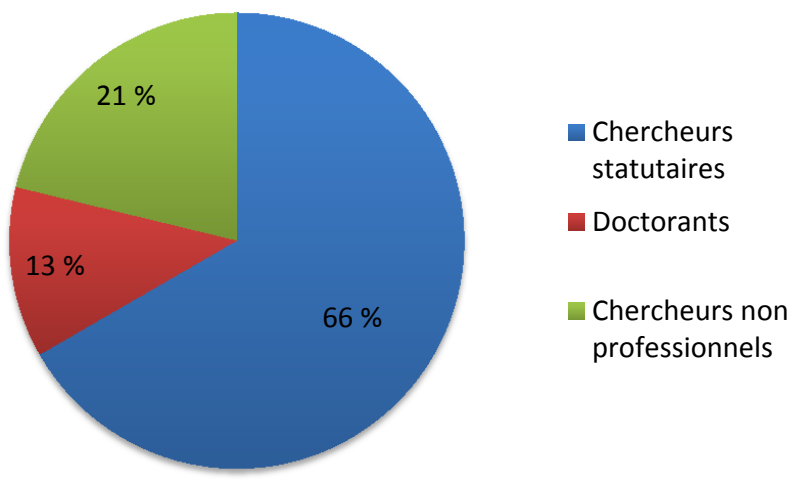

Répartition par provenance :

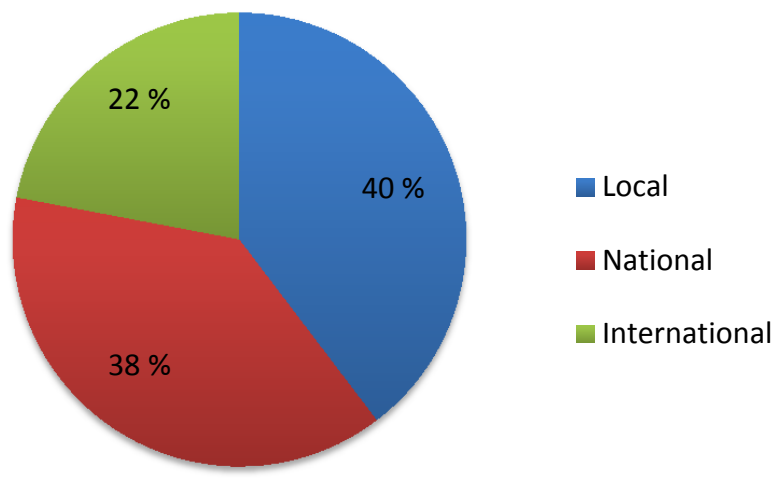

Répartition par sexe:

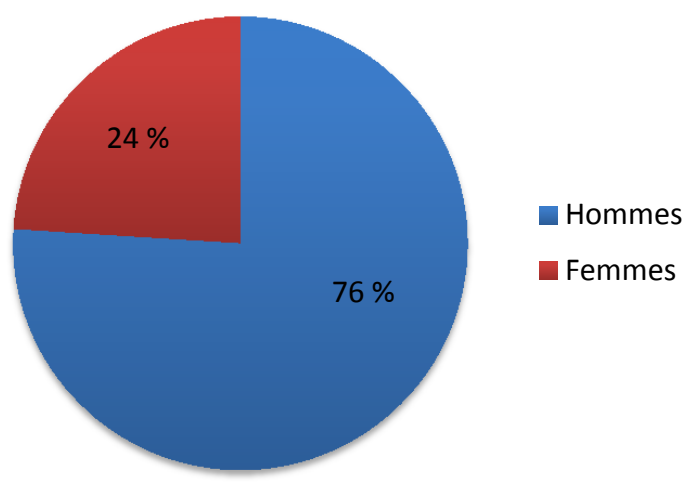


Évolution du nombre d'auteurs femmes :

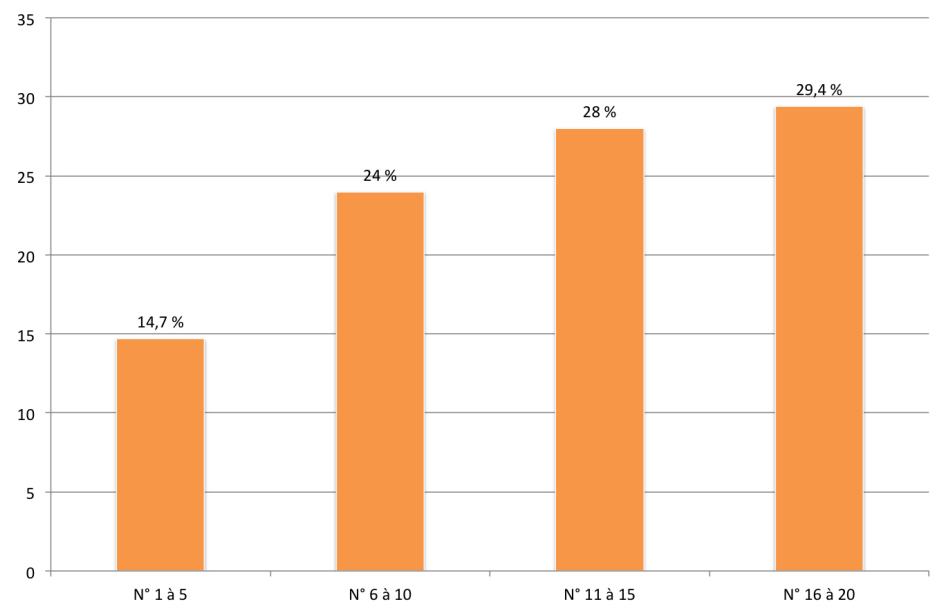

La Bretagne Linguistique c'est enfin une exposition :

Le $20^{\text {e }}$ numéro de La Bretagne Linguistique a été l'occasion d'une exposition inaugurée le 3 décembre 2014 lors d'une journée spéciale du séminaire. Elle avait pour titre "Brezhoneg war an dachenn - Figures de la transmission du breton » et proposait des séries de portraits photographiques de bretonnants réalisés par des étudiants de Master 1 Identités, pat r i moines, histoire de l'Université de Bretagne Occidentale, entre 2011 à 2014, dans le cadre d'enquêtes de terrain en dialectologie et sociolinguistique.

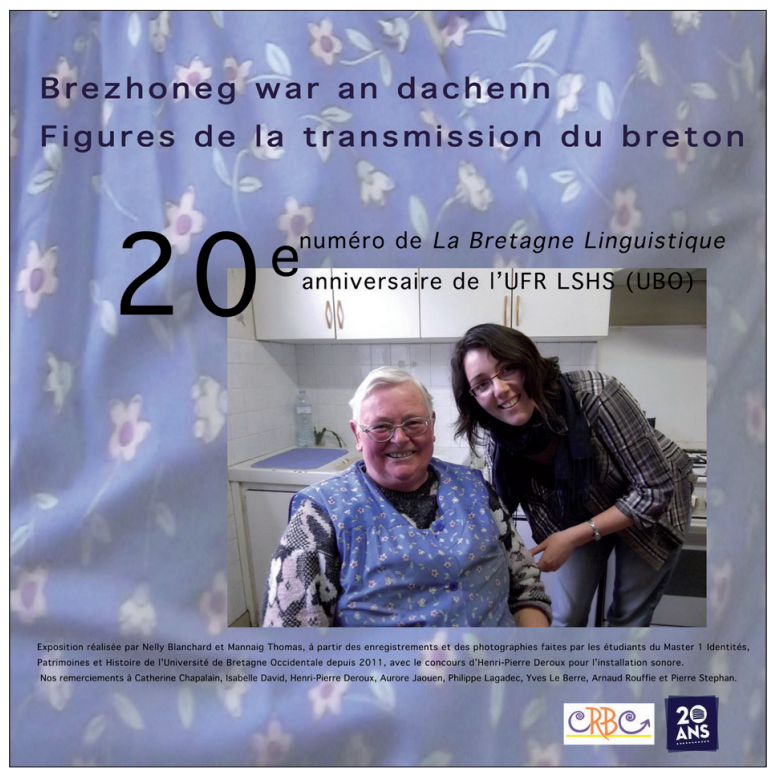

